\title{
Temas das Brincadeiras de Papéis na Educação Infantil
}

\author{
Role Play Themes in Early Childhood Education \\ Temáticas del Juego en la Educación Infantil
}

\section{Suzana Marcolino \& Suely Amaral Mello}

Universidade Estadual Paulista

http://dx.doi.org/10.1590/1982-370302432013 
Resumo: O objetivo do artigo é discutir os temas da brincadeira de papéis sociais na Educação Infantil, revelados por meio de análise conduzida com base nos estudos da Psicologia Histórico-Cultural. Para Elkonin, na idade pré-escolar a brincadeira atinge o auge de seu desenvolvimento, e se caracteriza pela criação de uma situação imaginária, pela presença de regras e de papéis sociais. Foram observadas situações de brincadeira de crianças de quatro anos e meio a cinco anos e meio em 11 escolas da rede municipal de uma cidade de médio porte do interior paulista. A partir do registro das observações, foram identificadas 27 cenas de brincadeira de papéis. A análise dos dados colhidos confirma a tese de Elkonin de que o desenvolvimento da brincadeira de papéis relaciona-se com o que a criança conhece de sua realidade, e indica a necessidade do estabelecimento de certas condições para que esse desenvolvimento ocorra na Educação Infantil. Nesse sentido, discute-se a necessidade de uma mediação do professor calcada na compreensão da riqueza de implicações que a brincadeira de papéis tem para a formação da pessoa.

Palavras-chave: Educação Infantil. Brincadeira de Papéis. Psicologia Histórico-Cultural. Desenvolvimento infantil.

Abstract: The goal of this paper is to identify themes of role play in Early Childhood Education. The analysis was based on studies of historical-cultural psychology. For Elkonin roleplay in preschool reaches its maximum development when children create an imaginary situation to interpret social roles oriented by rules. We observed role play situations with children from $4 \frac{1}{1} 2$ to $5 \frac{1}{2}$ years old in 11 municipal schools in a medium size city in the state of São Paulo. From the observations, we constructed 27 episodes of role play. The collected data analyses confirm Elkonin's thesis that role play development is related to the child social reality and indicate the necessity to establish certain conditions for this development in early childhood education. To overwhelm this condition, we argue that the teacher's mediation must be grounded on the understanding of the implications that role play has in the formation of children's personality.

Keywords: Early Childhood Education. Role Play Development. Historic-Cultural Psychology. Childhood development.

Resumen: El propósito de este artículo es identificar los temas del juego de roles en la Educación Infantil. El análisis se realizó sobre la base de los estudios de la psicología histórico-cultural. Para Elkonin, en niños de edad preescolar el juego alcanza su máximo desarrollo cuando los niños crean una situación imaginaria de interpretar roles sociales orientados por reglas. Hemos observado situaciones de juego de niños de cuatro años y medio a cinco años y medio en 11 escuelas municipales de una ciudad de tamaño medio del estado de São Paulo. Desde el registro de las observaciones, identificamos 27 escenas de juego de roles. El análisis de los datos recogidos confirma la tesis de Elkonin que el desarrollo del juego de roles se ubica en el conocimiento que los niños tienen de su realidad e indica la necesidad de establecer ciertas condiciones para el desarrollo que se realiza en el preescolar. Argumentamos la necesidad de la mediación basada en la comprensión de la riqueza de las implicaciones que el juego tiene en la formación de la persona.

Palabras clave: Educación Infantil. Desarrollo del Juego de Roles. Psicología Historico-Cultural. Desarrollo infantil. 
1 Este artigo faz um recorte na análise de dados colhidos para pesquisa de doutoramento, dedicado a verificar como a intervenção do professor na brincadeira pode afetar seu desenvolvimento.

2 Diferentes autores se referem à brincadeira de papéis sociais como brincadeira infantil, jogo dramático, brincadeira de papeis, brincadeira e brincadeira de faz de conta.

\section{Introdução ${ }^{1}$}

A teoria de Groos, desenvolvida no século XIX, e a de Buytendijk, produzida no século $X X$, que adotavam a brincadeira infanti ${ }^{2}$ como atividade natural da criança e fruto de impulsos internos, influenciaram muitos estudiosos da brincadeira infantil, o que levou Elkonin (2009) a afirmar que muito do que se desenvolveu sobre a análise dessa brincadeira no século XX constitui adendos ou modificações parciais daquelas teorias. Acolhendo, parcial ou integralmente, a ideia dos impulsos internos, alguns estudiosos entenderam a brincadeira de papéis sociais como produto de uma imaginação altamente desenvolvida e promulgaram a tese dos dois mundos: a criança quando brinca parte para um mundo imaginário, procurando escapar das imposições dos adultos (Elkonin, 2009).

Em sua análise, Elkonin parte das teses Vygotskianas, incorpora as contribuições de Alexix N. Leontiev e compreende a brincadeira infantil como atividade com origem histórica, que insere a criança nas relações sociais e, ao mesmo tempo, produz o desenvolvimento da consciência e da personalidade infantil, caracterizando-se como atividade guia do desenvolvimento da criança pré-escolar. Segundo o autor, dos três aos seis anos, atinge-se o nível mais desenvolvido da brincadeira infantil, denominado por ele de brincadeira de papéis. O elemento característico dessa forma da brincadeira é que as crianças criam uma situação imaginária para protagonizar papéis sociais balizados por regras. A base em que se apoiam os papéis interpretados nas ações lúdicas é a realidade social da criança. Segundo Elkoninn (2009), assim como são variadas as esferas da atividade humana, também são variados os temas da brincadeira de papéis. O tema "é o campo da realidade reconstituído pelas crianças" (Elkonin, 2009, p. 35).

Pesquisas recentes confirmam a tese de que as crianças reconstituem, na brincadeira, aquilo que conhecem da realidade. Teixeira (2008) apontou que as brincadeiras infantis na Ilha do Combu (PA) reproduzem aspectos do ambiente físico e as principais atividades adultas dos ribeirinhos. Seixas (2007) verificou que brincadeiras das crianças da llha dos Frades (BA) apresentam com muita frequência as temáticas ligadas ao mar e à pesca. Santos (2005) identificou a reconstituição da vida dos caminhoneiros em uma cidade do agreste sergipano, na qual a atividade econômica central é o transporte de carga pesada.

$\mathrm{Na}$ análise que fazemos, adotamos o pressuposto de que as crianças referem-se, na brincadeira de papéis, às relações sociais e às atividades humanas que conhecem, sendo que o espaço físico, os objetos e o tempo são condições que podem ou não favorecer o surgimento da interpretação daquelas esferas da vida que a criança conhece. Por isso, entendemos que esses aspectos são mediadores das possibilidades temáticas da brincadeira.

A motivação da criança para criar situações imaginárias para interpretar papéis relaciona-se com o momento de seu desenvolvimento. No primeiro ano de vida, todas as necessidades das crianças estão encarnadas no adulto e a atividade que impulsiona seu desenvolvimento é a comunicação emocional que se estabelece com esse adulto. A partir do segundo ano de vida, são os objetos e a atividade de exploração destes, no interior da atividade conjunta com os adultos, que adquirem força impulsionadora do desenvolvimento (Bozhóvich, 1987). Só na idade pré-escolar, descortina-se para a criança o mundo das relações sociais. Assim, manifesta-se nela a necessidade de agir como o adulto. Todavia, isso concretamente é impossível e ela satisfaz essa necessidade na brincadeira de papéis criando uma situação imaginária, para representar um tema, ou seja, relações e atividades humanas que conhece.

Essa nova atividade - a brincadeira de papéis - será responsável pelas mudanças mais importantes na personalidade da criança em idade pré-escolar. Ao assumir o papel de outrem, a criança começa a perceber seus limites e suas possibilidades em relação ao outro - em geral adulto - cujo papel 
assume na brincadeira. Nesse processo, avança a percepção de sua identidade por oposição ao outro: a relação entre o "eu imaginário" e o "eu real" desvela para ela com mais clareza seu eu real. Mais que isso, assumir um papel implica seguir as regras que caracterizam a atividade do personagem, o que implica no exercício do "eu devo" em relação ao "eu quero". Como afirma Vygotsky (2008), na brincadeira de papéis, a criança está sempre uma cabeça acima do seu tamanho, comportando-se como alguém em geral mais velho que ela. Assim, as regras do papel iniciam a criança no exercício da autodisciplina tão fundamental ao processo de aprendizagem e, consequentemente, de desenvolvimento.

O envolvimento de objetos para substituir outros ausentes e necessários à brincadeira e ao papel - o que exige a separação entre o campo real (óptico) e o campo do sentido (imaginário) - constitui na criança a função simbólica da consciência, essencial para a formação e desenvolvimento da imaginação que segundo Vygotsky (apud Kratsova \& Kratsov, 2010), aparece na arena do desenvolvimento psíquico quando a criança torna-se independente de sua própria percepção. Mais tarde, a função psíquica será também essencial no processo de apropriação da cultura escrita, instrumento cultural complexo que se apresenta como uma representação de segunda ordem e, por isso, sua apropriação é condicionada à formação dessa função psíquica superior na criança. Por todas essas possibilidades de promoção do desenvolvimento entre três e seis anos que criam bases para o máximo desenvolvimento humano na vida que se segue, seja como cidadão, seja comoacadêmico, é queVygotsky (2008) aponta a brincadeira de papéis sociais como a atividade que guia o desenvolvimento da inteligência e da personalidade na idade pré-escolar.

Entretanto, pesquisas tem demostrado que a brincadeira de papéis na prática educativa com crianças de três a seis anos enfrenta problemas. Às vezes, é atividade quase clandestina (Martins, 2009), quando o professor vê a brincadeira como perda de tempo e, comprometido com a preparação das crianças para o ensino fundamental, ocupa o tempo na escola com tarefas que antecipam a alfabetização. Em outras situações, muito semelhantes a essas, as crianças brincam "se der tempo", ou seja, em tempos curtos entre uma atividade dirigida e outra, quando não se chega ao pleno exercício da imaginação e à constituição de um argumento, à adoção plena de papéis e ao desenvolvimento de seu conteúdo (Marcolino, 2014). Em outras situações, o professor dirige o brincar, ou seja, adota o brincar desde que não seja "o brincar pelo brincar". Neste caso, o professor faz uso da brincadeira para fins didáticos, para ensinar conteúdos e habilidades, o que, como demonstrou V. V. Davidov (apud Kratsova \& Kratsov, 2010) não se sustenta, pois, não há brincadeira de papéis didática: por um lado a brincadeira perde seus traços essenciais e, por outro lado, a atividade didática perde suas características.

Por fim, há situações na escola da infância em que a brincadeira de papéis sofre $o$ abandono completo do professor que, por não entender o papel da brincadeira no desenvolvimento humano na infância, a trata como atividade de segunda categoria que não merece sua intervenção para que as crianças ampliem as temáticas vivenciadas na brincadeira. Em condições como estas, não causa estranhamento que as crianças entendam que brincar é inapropriado na escola, tal como identificou Silva (2008), ao entrevistar crianças de quatro a sete anos de uma escola municipal da rede pública de Catalão, Goiás.

Compreendendo que conhecer os temas da brincadeira na Educação Infantil pode apontar as condições criadas para esta atividade guia, a pesquisa que deu origem a este artigo objetivou conhecer temas da brincadeira de papéis nesse espaço/tempo de desenvolvimento da infância, por meio da observação da brincadeira de papéis de crianças de quatro anos e meio e cinco anos e meio. Consideramos que essa discussão abre caminho para dialogar sobre tipos de mediação que a Educação Infantil pode proporcionar de modo a potencializar o desenvolvimento da atividade guia infantil e, com isso, o próprio desenvolvimento humano na infância pré-escolar. 


\section{Metodologia}

Entendemos que a brincadeira de papéis é a principal categoria para análise do desenvolvimento criança, uma vez que capta a unidade entre o social/cultural/histórico e o interno/subjetivo do ser em desenvolvimento. Com sua observação e análise buscamos encontrar elementos das condições criadas para a bricadeira e seu desenvolvimento temático, partindo do pressuposto de que a atividade tem a qualidade que a mediação oferece. Na escola de Educação Infantil, essa mediação ocorre, essencialmente, pela organização das condiçãos para esse brincar.

Consideramos que, ao observar a brincadeira em diferentes mediações, apreendemos a brincadeira em certo momento, produção mais imediata de uma mediação. Dessa forma, o dado produzido pela observação revela a brincadeira em sua imediaticidade, não em seu movimento. Apontamos para esse fato, pois conjecturamos que, em muitas situações observadas, a brincadeira de papéis poderia aparecer sob outra forma de desenvolvimento se as condições fossem outras.

Assim, foram observadas brincadeiras de crianças de quatro anos e meio a cinco anos e meio matriculadas nas etapas I e II de onze escolas da rede municipal de Educação Infantil de uma cidade de porte médio, no centro-oeste paulista.

Uma vez que as pesquisas indicam que as crianças brincam das temáticas que conhecem em seu entorno social, selecionamos escolas inseridas em contextos diferentes: escolas de distritos; da zona rural; de regiões centrais da cidade; de regiões periféricas, carentes de serviços públicos.

Em cada turma permanecemos por cinco dias e acompanhamos a turma durante todo o período. Esclaremos que os periodos das turmas observadas foram manhã ou tarde, sendo que nehuma turma de periodo integral foi observada. Tanto quanto possível, preservou-se a naturalidade dos momentos observados. Não interferímos nas situações. No primeiro dia, apresentávamo-nos às crianças, falávamos sobre o intuito da visita e, tomávamos assento em local discreto com um protocolo de observação em mãos, atitudes, essas últimas, que se repetiam nos demais dias de observação.

O protocolo de observação foi o instrumento utilizado para registro das informações. Nele fizemos uma representação gráfica da organização do espaço, como, por exemplo, se as carteiras e cadeiras eram afastadas ou se haviam "cantos" e anotações referentes aos temas e ao conteúdo das brincadeiras de papéis. Logo após o fim da observação, elaborávamos uma ata descritiva.

Além de anotações referentes aos temas, também fizemos anotações sobre o conteúdo. Segundo Elkonin (2009), para as crianças mais novas, brincar é centralmente reproduzir ações com os objetos, sem, ainda, assumir um papel. A partir de cinco anos, cada vez mais as crianças preocupam-se em representar as relações do papel, sendo sua definição na brincadeira um momento importante, pois demonstra que o papel já está mais delineado para as crianças. Nesse momento de desenvolvimento da brincadeira é comum as crianças anunciarem os temas, o que não ocorre na fase em que os papéis são interpretados por meio da reprodução de ações com objetos como, por exemplo, mexer uma colher em panela de brinquedo, fazendo de conta que cozinha. Assim, quando o tema não era anunciado pelas crianças, as cenas foram nomeadas a partir do conteúdo, ou seja, da forma como representavam os papéis.

A partir das descrições das observações, construímos vinte e sete cenas de brincadeiras de papéis. Para caracterizar uma situação de brincadeira como cena de brincadeira de papel social tomamos como critérios: (i) a execução de ações lúdicas, ou seja, aquelas em que as crianças representam ações de um papel, como fazer que lava a louça ou fala no telefone, mesmo que se apresentassem de forma isolada e desarticulada; (ii) a definição de papéis pelas crianças; (iii) interpretação das relações sociais de um papel. A ocorrência de um dos critérios foi considerada suficiente 
para se definir uma situação de brincadeira como uma cena de brincadeira de papéis sociais, pois o fato de observarmos crianças de idades diferentes colocou-nos diante de diferentes fases do desenvolvimento da brincadeira infantil.

Criamos a categoria condição especialmente criada para a brincadeira de papéis. Essa categoria descreve condições e circunstâncias particulares criadas para a brincadeira e contemplam desde a permissão de tempo para as crianças brincarem até a organização de um espaço específico, com brinquedos/objetos e intervenções do professor para ampliar as possibilidades da brincadeira. O núcleo da categoria contém a ideia de que os temas da brincadeira surgem por meio das diferentes situações criadas.

\section{Resultados}

Das onze escolas observadas, em duas não foi possível captar cenas de brincadeira de papéis em qualquer nível de desenvolvimento. Nessas escolas não havia nenhuma condição especial preparada para a brincadeira de papéis sociais. Os momentos em que as crianças podiam brincar se davam no início e no final do período escolar em espaço aberto e sem materiais. Nessa situação, foram observadas brincadeiras de movimento, como pega-pega, esconde-esconde, chute a gol. Esse fato indica que, pelas características da brincadeira de papéis, na escola de Educação Infantil, ela demanda a organização intencional de tempo e espaço e objetos para que possa surgir.

Os temas e a frequência dos episódios captados, num total de 27, se seguem: Casinha (11), Salão de beleza (3), Tiroteio (2), Super-heróis (2), Passeio ao centro da cidade (1), Soltar pipa (1), Escola (1), Entregador de pizza (1), Acidente de carro (1), Oficina (1), Conversa ao telefone (1), Escritório (1). Os temas expressam o conhecimento que as crianças têm do mundo e as crianças em idade pré-escolar podem conhecer o mundo a partir de seus múltiplos vínculos com o real.
O tema mais frequente - e presente em nove das escolas - foi a brincadeira de casinha (11 das 27 cenas registradas), na qual as crianças representam cuidados com a casa e as relações familiares. Esse tema foi observado tanto nas escolas que adotam a estratégia dos cantos, como naquelas que apenas põem à disposição brinquedos desse tema (como panelas, pratos, talheres, copos, bonecas).

Na brincadeira de salão de beleza (três das 27 cenas), duas ocorreram em escolas que utilizam a estratégia de cantos - um deles com brinquedos referentes ao tema - e uma aconteceu em uma escola que oferecia brinquedos sem um lugar específico.

As cenas de passeio ao centro da cidade (duas em 27 cenas) foram observadas em escolas localizadas em distritos, portanto, longe do centro da cidade. Ir ao centro da cidade significa para essas crianças um evento significativo, pois não ocorre todos os dias, mas, em geral, quando os pais recebem o salário e vão até a cidade para fazer as compras do mês. Esse tema surgiu por iniciativa das crianças utilizando brinquedos oferecidos na sala. As crianças organizam a situação imaginária, criando, por exemplo, o ônibus ou o carro com cadeiras enfileiradas - condução para o passeio - a partir do que definem o enredo da brincadeira.

Em um dos episódios de super-heróis (duas das 27 cenas), as crianças representaram a luta de um herói contra o vilão de um desenho animado. No outro, ambos eram heróis de desenhos animados. As cenas acontecem quando o professor afasta mesas e cadeiras e oferece brinquedos. Chamamos atenção para o fato de não existir brinquedos do tema na situação. Nota-se, pois, que desenhos e filmes - e podemos supor que também a literatura e o teatro - sugerem temas para a brincadeira. Possivelmente os desenhos animados e as histórias de super-heróis influenciem os temas e também os conteúdos do brincar, porque apresentam de forma viva as relações entre os personagens. Particularmente o papel de super-herói é atrativo para as crianças por ser central, exigir movimentação intensa e interagir com vários personagens na trama. 
Nas cenas que denominamos tiroteio (duas das 27 cenas registradas), as crianças criavam armas com peças de jogos de montar ou as representavam com objetos substitutos e interpretavam a tentativa de alvejar os demais personagens. Esse é um tema que ocorre contra a vontade do professor, sendo proibido nas turmas observadas. Nos dois episódios, ocorreu a intervenção das professoras, encerrando a brincadeira. Em uma das escolas em que observamos este tema, as notícias sobre eventos violentos eram constantes no bairro e a agressão física, comum entre as crianças na escola.

A cena soltar pipa (uma em 27 cenas) foi sugerida por um garoto no momento que brincavam no parque, recriando um tipo de brincadeira ainda comum entre adultos de bairros periféricos das cidades, como é o bairro onde se localiza a escola.

Também a entrega de pizza (uma em 27 cenas) é a reconstituição de uma face da vida cotidiana das crianças. A brincadeira surgiu quando crianças brincavam com brinquedos do tema casinha disponibilizados pelo professor e um garoto afirma-se no papel: "Sou o entregador de pizza, venho entregar as pizzas". Faz de conta que dirige uma moto, para na frente da casa e buzina.

A cena de acidente de carro (uma em 27 cenas) é extremamente curta e surge na situação em que brinquedos são oferecidos na sala. Uma garota deita no chão, pede socorro, diz que foi atropelada, outra faz de conta que é a ambulância, mas antes que a ambulância chegue, a garota que faz o papel de acidentada levanta-se e parte para outra atividade. Vale destacar que a escola localiza-se nas margens de uma rodovia.

A cena escola (uma em 27 cenas) foi captada em uma situação em que a professora disponibilizou brinquedos na sala para as crianças. Entre os brinquedos, havia livros que uma garota começou a manipular e sugeriu para a amiga: "Vamos brincar de escola?". No entanto, a cena não se desenvolve, a garota folheia o livro e a amiga sai da situação.
Conversa ao telefone (uma em 27 cenas) foi observada em situação similar à cena descrita acima. A professora dispõe brinquedos em farta quantidade e uma criança pega um telefone e interpreta uma conversa com alguém, sem dar continuidade à cena.

A cena escritório (uma em 27 cenas) e oficina (uma em 27 cenas) ocorreram em uma sala em que a professora organizava a estratégia de cantos, com brinquedos de diferentes temáticas em zonas circunscritas da sala. Embora as cenas sejam mais longas, se comparadas com a cena de escola e acidente de carro, as crianças interpretam poucas relações. $\mathrm{Na}$ cena no escritório, basicamente apertam as teclas de teclados de computadores e interpretam falar ao telefone.

\section{Discussão}

O surgimento da brincadeira na escola de educação infantil exige a organização de condições adequadas. Navarro e Prodócimo (2012) destacam a participação da professora na organização dos momentos dedicados à brincadeira de papéis. Teixeira (2012) aponta para a importância da organização do espaço, dos grupos e dos materiais a fim de estabelecer uma condição favorável para a brincadeira. Mukhina (1986) destaca a existência de tempo livre que possibilite a iniciativa das crianças, a presença de materiais que provoquem a brincadeira e o conhecimento pelas crianças de atividades humanas diversas que criem referências para a situação imaginária e para os papéis na brincadeira. Petroviski (1980) aponta a importância da intervenção do professor nos casos em que a situação imaginária não avança em seu argumento, repetindo-se sempre da mesma forma em dias consecutivos. Para o autor, a imaginação, como o pensamento, surge em situações problemáticas, ou seja, nos casos em que é preciso buscar novas soluções para problemas enfrentados e, desse ponto de vista, o professor intervém na brincadeira para inserir, como personagem da situação imaginária, situações problemáticas que exijam novos desdobramentos do enredo. 
Por isso, ao olhar para os dados coletados, um primeiro elemento a ser discutido é se a quantidade de cenas capturadas revela algo sobre a mediação da brincadeira na escola de Educação Infantil. Nesse sentido, Barros (2009), que estudou as transformações ocorridas no brincar na transição da Educação Infantil para o Ensino Fundamental, supondo que a brincadeira diminuiria de frequência, evidenciou, com seus dados, o contrário: as crianças brincam mais no Ensino Fundamental, devido a maior possibilidade de tempo livre que as próprias crianças encontram formas de viabilizar. $\mathrm{Na}$ pesquisa que dá origem a este artigo, em que se buscou observar brincadeiras de papéis sociais, encontrá-las não foi evento frequente. Não se encontrou, senão em uma escola, um tempo previsto para a brincadeira no planejamento das professoras. Retomando as contribuições de pesquisas realizadas sobre essa questão, o tempo livre é elemento fundamental da mediação proporcionada pelo professor (Mukhina, 1986). A brincadeira, de um modo geral, é vista como uma atividade de segunda categoria, uma vez que não resulta num produto que possa ser apresentado aos pais e aos superiores dos professores que veem na produção de materiais uma forma de fiscalizar o trabalho docente.

Algumas situações por nós observadas evidenciaram dificuldades na compreensão da brincadeira de papéis por parte das professoras, o que obstaculiza a ação mediadora. Em uma situação, a professora anuncia que vai brincar de casinha com as crianças. Em seguida, pega uma jarra com suco e copos, divide o suco pelos copos e solicita que as crianças respondam perguntas de conhecimento matemático. Também não foi raro, em nossa presença, professoras iniciarem brincadeiras de roda, amarelinha e incentivarem as crianças a cantar e a explorar possibilidades da massa de modelar entendendo que assim contemplavam a brincadeira de papéis. Identificamos, ainda, que, de forma geral, não há, nas escolas, uma construção comum sobre diretrizes para organizar essa atividade: cada professor faz, ou, não faz, da forma como conceber. Apenas em uma escola havia uma organização coletiva que utilizava a estratégia dos cantos.
Assim, entendemos que o número de cenas (27) captadas no tempo em que permanecemos nas escolas poderia ser maior, se as condições oferecidas para essa atividade fossem outras. A pobreza numérica de cenas captadas está diretamente ligada à pobreza de situações especiais criadas para a brincadeira, possivelmente, fruto da não compreensão sobre essa atividade e seu lugar no desenvolvimento na infância. Essa pobreza numérica de cenas captadas vai ao encontro dos achados de outras pesquisas realizadas desde os anos 1990, que constatam a dificuldade da Educação Infantil em incorporar o brincar no trabalho pedagógico (Carleto, 2000; Carvalho, 1999; Martins, 2009; Rocha, 1994; Wajskop, 1990).

Para a Psicologia Histórico-Cultural é essencial que as crianças se envolvam em brincadeiras de papéis e que estas se apresentem com vários temas: temáticas diferentes podem exigir a criação de situações imaginárias novas e mais complexas, papéis mais complexos e regras mais elaboradas, envolvendo funções psíquicas sofisticadas como o controle da vontade, a percepção da própria identidade por oposição ao papel representado e a imaginação, além de exigir o exercício da memória, da linguagem oral, do pensamento - todas elas possibilidades de desenvolvimento na criança pré-escolar -, assim como o aprendizado da vida em grupo e da solução de problemas como inciativas tomadas pelas crianças independentemente do adulto.

$\mathrm{Na}$ análise dos temas, chama a atenção, a preponderância do tema casinha em todas as nove escolas onde ocorreram brincadeiras de papéis, possivelmente por fazer parte da vida cotidiana diretamente acessível às crianças. Entretanto, não pode escapar à análise o fato de todas as escolas disponibilizarem brinquedos referentes a esse tema, atitude que sugere papéis e define temas para a brincadeira.

Brougère (1998) analisa as relações históricas entre brincadeira e educação e explica que favorecer materiais que imitam a vida cotidiana em espaços específicos é justificado pedagogicamente por educadores pela necessidade de limitar a brincadeira e confrontar 
a criança com o real. Em nossa análise, essa justificativa converge para a teoria dos dois mundos na qual a brincadeira é uma fuga do mundo das regras adultas para um mundo imaginário de pura fantasia, quando a escola procura confrontar a criança com o mundo real por meio dos objetos e da forma como se organiza o espaço para brincar. Há, nessa posição, a ideia de que realidade e imaginação se contrapõem. Do ponto de vista da Psicologia Histórico-Cultural, a oposição entre realidade e imaginação, não se sustenta. Para Vigotski (2012), a relação entre imaginação e realidade está na base da explicação de como se produz a atividade criadora. A atividade criadora da imaginação se encontra em relação direta com a riqueza e variedade da experiência acumulada pelo ser humano, pois é sob essa experiência que se edifica a imaginação: quanto mais rica for a experiência, tanto maior será o material de que dispõe a imaginação. A conclusão pedagógica a que Vygotski chega é:

(...) sobre a necessidade de ampliar a experiência da criança se queremos proporcionar base suficientemente sólida para a sua atividade criadora. Quanto mais velha, quanto mais escutar e experimentar, quanto mais aprender e assimilar, mais elementos reais terá em sua experiência, tanto mais considerável e produtiva será a igualdade das circunstâncias, da atividade de sua imaginação. (Vigotski, 2012, p. 18, tradução nossa)

Conforme este aporte teórico, não se justifica a preponderância de brinquedos que sugerem uma temática específica com intuito de confrontar a criança com o real, pois o real relaciona-se dialeticamente com a atividade criadora. A intervenção pedagógica intencional na brincadeira de papéis deve preocupar-se em apresentar a atividade humana em suas múltiplas possibilidades. Desse ponto de vista, ao não ser entendida em sua essência pedagógica pelo professor e ser tomada como uma atividade de segunda categoria, a brincadeira de papéis não merece do professor uma preocupação em relação ao material disponibilizado para essa atividade. Nessa perspectiva, parece preponderar uma tradição de disponibilizar material de casinha para as meninas e carrinhos para os meninos, em lugar da orientação dessa escolha por uma intencionalidade docente.

Da mesma forma acontece com a ampliação do conhecimento pelas crianças acerca das diferentes atividades humanas. Numa situação de valorização da brincadeira de papéis, a organização de atividades que ampliassem o conhecimento das crianças acerca da diversidade das atividades humanas deveria ser objeto da prática docente intencional. $\mathrm{Na}$ ausência dessa valorização, essa prática não acontece e as crianças ficam restritas aos papéis conhecidos no cotidiano.

Uma atenção especial aos objetos oferecidos é necessária quando se discute o desenvolvimento do tema da brincadeira de papéis, pois sua variedade é condição para que a criança variar as temáticas da brincadeira. Para isso, será preciso um suporte constante do professor - inserindo novos objetos, retirando outros que já não despertam interesse -, sempre de modo a incentivar o surgimento de novas temáticas. Tal ação só é possível quando o professor acompanha a brincadeira das crianças, observando-a atentamente.

Podemos, ainda, enxergar a forte presença da brincadeira de casinha a partir da perspectiva do desenvolvimento ontogenético da brincadeira infantil. O primeiro e intrigante campo das relações humanas que a maioria das crianças conhece mais profundamente é o das relações familiares. Sendo a motivação para a brincadeira a representação das relações sociais dos papéis (Elkonin, 2009; Vygotski, 2008), é de se esperar que as relações familiares sejam um tema da brincadeira infantil. Estudos sobre o desenvolvimento do papel demonstram que primeiro as crianças tendem a interpretar o papel dos adultos íntimos, os pais para a maioria das crianças, e, conforme se amplia o círculo de relações sociais, novos papéis passam a ser interpretados (Elkonin, 2009).

Entretanto, essa explicação não deve ter como consequência pedagógica a prioridade a esse tema, impedindo que outros se desenvolvam. 
Na perspectiva histórico-cultural do desenvolvimento humano, interessa que a criança possa vivenciar variadas relações. Nesse sentido, vale destacar a pesquisa de Usova (citada por Elkonin, 2009) que contemplou o desenvolvimento dos temas da brincadeira observando crianças de três a cinco anos. A investigadora constatou que um fator importante para o desenvolvimento dos temas na brincadeira é a afinidade do tema lúdico com a experiência da criança. Sendo assim, a pobreza de experiências constitui um obstáculo para que se desenvolva a temática da brincadeira, tanto no que diz respeito ao desenvolvimento do argumento, quanto à possibilidade de novos temas surgirem e se desenvolverem. Em uma condição em que as crianças têm sua experiência ampliada, notou-se que as crianças de três e quatro anos representam ações da vida cotidiana, mas as crianças de cinco anos recorrem a eventos sociais e temas literários.

Ao analisar as possíveis implicações da ausência de sugestão de novos temas, percebemos que, na ausência de temas novos que demandem o desenvolvimento de situações imaginárias diferentes, as crianças deixam de criar novas situações imaginárias e se desinteressam da atividade. Nesse sentido, Ignatiev (1960) afirma que toda atividade criadora traz consigo a necessidade de resolver problemas e, este é um elemento da brincadeira de papéis posto na criação da situação imaginária. Nessa perspectiva, os temas geram a necessidade de resolução de problemas por meio da combinação de elementos da realidade conhecidos pela criança. Assim, quando brincam de viajar, por exemplo, as crianças devem decidir quem irá na viagem, como chegarão ao local escolhido, o que levar, onde ficarão hospedadas e também quais objetos e brinquedos podem ser usados na criação da situação imaginária. Por isso, criar situações de brincadeiras de papéis sociais em que as crianças tenham de resolver problemas leva ao desenvolvimento da imaginação como função psíquica superior: contribui para superar a imaginação involuntária rumo ao desenvolvimento da imaginação voluntária. Diferente da capacidade de criar imagens ao ouvir uma história - quando a criança não tem controle sobre o processo de criação e, por isso, chamamos de imaginação involuntária -, a imaginação voluntária caracteriza-se pela intenção deliberada de criar algo (Ignatiev, 1960). Ao resolver problemas criados pela situação imaginária, as crianças exercitam o controle da imaginação, fundamental para o desenvolvimento da imaginação voluntária.

Em relação aos temas que sugerem violência, chama nossa atenção a atitude das professoras de proibir sempre brincadeiras em que as crianças simulavam atirar nos companheiros. Uma vez que os temas da brincadeira de papéis sociais emergem da realidade social, não estão fora desse mundo e nem em lugar recôndito do psiquismo infantil, o sentido dessa atitude é que questões sociais complexas devem ficar fora da escola - ainda que sejam parte da vida das crianças. Dessa forma, a escola acaba apartando-se da realidade social e não a discutindo com as crianças, nem se posicionando frente a ela. Como explica Martins (2010), a violência é intrínseca à organização da sociedade capitalista, convertendo-se em modo de vida e forma das pessoas se relacionarem. Vygostki (1995) discute o fato de que a consciência infantil reflete de forma ingênua, sem crítica, a realidade social. Assim, as crianças interpretam na brincadeira as relações sociais alienadas da sociedade capitalista, pois são estas que estão disponíveis e dessas relações sociais tomam consciência na brincadeira de papéis sociais. A discussão e problematização dos valores representados nas brincadeiras de papéis - momento essencial na formação e desenvolvimento dos valores, atitudes e sentimentos das crianças - devem acontecer em momento seguinte à atividade, como parte do processo de compartilhamento coletivo das atividades realizadas em pequenos grupos e devem ser dirigidos pelo professor. Para isso, o professor atua na brincadeira de papéis não apenas como parceiro mais experiente, mas como observador das relações instauradas na brincadeira e que carregam consigo modos de ver e viver as relações sociais e de explicar fenômenos físicos e sociais muitas vezes envoltos em preconceitos ou carentes de uma explicação científica - o que deve ser problematizado pela escola em conjunto com as crianças. 
A atuação do adulto na problematização dessas relações é elemento de educação fundamental da conduta das crianças. Em outras palavras, a possibilidade de desenvolvimento de uma consciência crítica das relações sociais está ligada, necessariamente, à intervenção do professor na brincadeira de papéis. Segundo Vygotski (1995), o adulto empresta seu psiquismo à criança, auxiliando-a a compreender aquilo que seu desenvolvimento atual ainda não permite. De forma similar, na brincadeira o professor empresta seu psiquismo às crianças ajudando-as a refletir sobre as relações sociais, os valores e os sentimentos que vão internalizando. Por isso, para Elkonin (1987), o professor deve observar não apenas os temas que as crianças brincam, mas também, o conteúdo representado na brincadeira de papéis sociais, pois este reflete condutas fundadas em normas e valores sociais. Nesse sentido, faz-se necessário propiciar uma assimilação crítica dos valores da sociedade atual demonstrando para as crianças que formas de relacionamento e normas de conduta são sociais e históricas e passíveis de mudança.

Em relação à associação entre condições criadas e surgimento dos temas da brincadeira, notamos que, na condição de oferecer objetos e oportunidade de brincar no parque, registramos o surgimento de temas propostos pelas crianças, enquanto que na brincadeira nos cantos organizados nas salas, as brincadeiras tendem a ser aquelas propostas pelos objetos e brinquedos ali organizados. Vale mencionar, que nas escolas em que observamos os cantos, esses não eram fixos, ou seja, eram organizados pelo professor na hora de brincar e, continham brinquedos de um determinado tema.

Sobre os temas propostos pelas crianças, é importante mencionar que muitos deles não se desenvolvem o quanto poderiam, pois adotam cenas muito curtas, como no caso das cenas escola e acidente de carro. No caso de uma das cenas de passeio ao centro da cidade, ela se desenvolve com poucas ações e relações e argumento pobre: as crianças apenas ficam no carro ou no ônibus, mas não chegam à cidade para realizarem as compras ou o passeio planejado. Esses temas poderiam se desenvolver mais ricamente com o apoio do professor ajudando a organizar o espaço, o tempo, apresentando objetos e mesmo ajudando no planejamento oral da atividade com as crianças quando se poderiam resgatar as ações realizadas nas visitas à cidade. Entendemos que pela oferta de objetos, mesmo que ainda pobre, e pelo conhecimento maior que as crianças têm do ambiente casa, a brincadeira do tema casinha seja majoritária.

A partir da análise dos temas, pensamos que uma condição desenvolvente para a brincadeira de papéis pode conter tanto sugestões do professor - seja organizando brinquedos e objetos em espaços da sala ou pela proposta direta de um tema de brincadeira, por meio de visitas e passeios que ampliem o conhecimento das crianças acerca da atividade humana e das relações sociais - como também acolher temas que reflitam as vivências das crianças, dando apoio para que eles se desenvolvam por meio da apresentação dos objetos, da organização do espaço e do tempo e pela exploração das vivências das crianças.

Destacamos que nas escolas pertencentes à zona rural, não captamos cenas em que as crianças interpretassem facetas da vida no campo. Sem tempo para a brincadeira na organização do tempo escolar, sem condições dadas para a brincadeira na escola, os modelos adotados foram ações e relações da vida urbana, que não tematizam vivências de crianças que moram no campo.

Vale ainda analisar, embora o presente trabaIho tenha como foco principal os temas das brincadeiras, alguns apontamentos sobre seu conteúdo, ou seja, sobre como as crianças desenvolvem as relações de um determinado tema. Ao comparar o conteúdo da brincadeira de papéis entre crianças de quatro anos e meio e cinco anos, observamos pouca diferença no que diz respeito à interpretação dos papéis, $\mathrm{o}$ que pode significar uma paralisia no desenvolvimento da brincadeira. Mesmo no caso da brincadeira de casinha, percebemos que a situação imaginária não se expande, ficando 
as ações restritas ao ambiente da cozinha. Apenas em uma cena observada, as ações se apresentavam encadeadas e o conteúdo dos papéis representava relações sociais além de ações isoladas com brinquedos. De um modo geral, podemos dizer que as ações observadas - lavar a louça, fazer comida sem servi-la a ninguém - não contribuem para ampliar o argumento da brincadeira. Também verificamos, que a grande maioria das cenas, repetem o mesmo conteúdo sem se enriquecer e sem mudar ao longo das idades. Isso pode resultar do fato da escola oferecer sempre o mesmo espaço, o mesmo tempo e os mesmos objetos. Some-se a isso a não intervenção do professor com propostas de atividades que ampliem a percepção das relações humanas e mesmo criando situações problema. Essa ausência de intencionalidade docente não desafia as crianças a ampliar os conteúdos interpretados na brincadeira.

Alguns obstáculos ao brincar são visíveis em nossa sociedade: a falta de espaços públicos, o fato da televisão substituir momentos de brincar, a violência dos grandes centros urbanos que comprime as crianças no espaço doméstico, a antecipação dos processos de escolarização com a perspectiva ilusória de que se pode acelerar o desenvolvimento intelectual das crianças antecipando o treino da escrita (Mello, 2007). No entanto, dado o lugar essencial da brincadeira de papéis sociais para o desenvolvimento, é necessário superar esses obstáculos e produzir as condições adequadas ao seu pleno desenvolvimento na escola de Educação Infantil onde as crianças vivem coletivamente uma parte significativa de seu dia.

Como lembra Zaporózhets, (1987, p.246), a aprendizagem na escola da infância acontece e assume um caráter desenvolvente quando:

(...) os métodos de educação se estruturam em correspondência com as particularidades psicofisiológicas da idade pré-escolar, quando, por exemplo, o ensino dos pré-escolares não se realiza sob a forma da tradicional lição escolar, mas sob a forma do jogo, da observação direta e prática, de diferentes tipos de atividade prática, plástica, etc.. (Zaporózhets, 1987, p. 246, tradução nossa)
No entanto, como aponta Mello (2007) o quadro típico das escolas de Educação Infantil manifesta a ideia de que é desejável antecipar a aprendizagem das crianças com espaços, rotinas, organização do tempo e relações próprias do Ensino Fundamental, ignorando as formas de aprender das crianças pequenas e desprezando as possibilidades de aprendizagem e desenvolvimento criadas pela brincadeira de papéis.

\section{Considerações Finais}

Os dados captados e a análise que fizemos deles, indicam que a brincadeira na Educação Infantil, embora seja atividade rica de possibilidades para o desenvolvimento, ainda recebe um tratamento pobre, implicando diretamente na pouca variedade temática que observamos.

Para Martins e Eidt (2010), o enriquecimento das atividades humanas se coloca como principal fundamento para o desenvolvimento humano, especialmente se considerarmos o fenômeno da alienação que separa cada ser humano da riqueza espiritual e material produzida historicamente pelos seres humanos (Martins \& Eidt, 2010; Tonet, 2009). Sendo assim, enriquecer a atividade das crianças é parte essencial do trabalho docente. Por isso, consideramos que o trabalho intencional do professor com a brincadeira de papéis está em dedicar tempo, criar e ampliar espaços e objetos. Por outro lado, se considerarmos que, na brincadeira de papéis sociais, as crianças interpretam aquilo que conhecem da realidade social, promover o enriquecimento dessa atividade implica ampliar o conhecimento das crianças sobre as várias esferas da atividade humana, para que elas possam, com apoio do trabalho intencional do professor, criar novas e diversificadas situações imaginárias.

Compreender a brincadeira de papéis como atividade guia da idade pré-escolar, suas especificidades e seu desenvolvimento é condição para que o professor possa construir uma intervenção desenvolvente sobre o brincar. Para tanto, a formação inicial e continuada deve possibilitar a construção de uma prática 
pedagógica referente à brincadeira de papéis sociais fundamentada cientificamente. A ciência psicológica poderá contribuir para isso na medida em que auxilia na crítica a modelos abstratos de explicação do desenvolvimento infantil que compreendem o brincar como atividade natural da criança, provocando a reflexão sobre como as atividades infantis e o modo que elas se dão repercutem na aprendizagem e no desenvolvimento das crianças na escola.

Também consideramos ser necessário avançar em estudos empíricos que possam revelar os contornos que o brincar assume em nossa sociedade atualmente e que especifiquem como determinadas condições podem afetar seu desenvolvimento.

Nesse sentido, um tema de pesquisa importante diz respeito ao desenvolvimento do conteúdo da brincadeira, ou seja, como as crianças interpretam as relações dos papéis.
Segundo Elkonin (2009), este é um aspecto central da brincadeira e pode revelar muito sobre o brincar em uma determinada época, bem como sobre a apropriação que as crianças fazem da realidade e sobre as circunstâncias atuais oferecidas na escola da infância para o desenvolvimento infantil. Pesquisas que avancem a percepção de como determinadas condições influenciam o desenvolvimento do brincar podem contribuir efetivamente para criar condições para de fato incorporar o brincar de maneira desenvolvente no trabalho educativo com as crianças pequenas.

Por fim, destacamos a relevância do referencial da Psicologia Histórico-Cultural como quadro teórico-metodológico profícuo para a pesquisa sobre o desenvolvimento humano nos contextos educativos, pois o entendimento da atividade infantil como social e histórica pode contribuir para o entendimento do papel da educação no desenvolvimento da personalidade da criança. 


\section{Suzana Marcolino}

Doutora em Educação pela Universidade Estadual Paulista, Marília - SP. Brasil.

E-mail: marcolino.suzana@gmail.com

\section{Suely Amaral Mello}

Doutora em Educação pela Universidade Federal de São Carlos, São Paulo - SP. Brasil. Docente da Universidade Estadual Paulista, Marília - SP. Brasil.

E-mail: não informado pela autora

\section{Endereço para envio de correspondência:}

Rua Dom Lino Deodato Rodrigues de Carvalho no 1057-B. Jardim Proença. CEP: 13100-406. Campinas - SP. Brasil.

Recebido 17/12/2013, Reformulado 11/12/2014, Aprovado 20/01/2015. 
Barros, F. C. O.M. (2009). Cadê o brincar? São Paulo, SP: Cultura Acadêmica.

Bozhóvich. L. (1987) Las etapas de formacion de la personalidade em la ontogenesis. In V. Davidov, \& M. Suare (Orgs.), La psicología evolutiva y pedagógica en la URSS: Antología (pp. 5-24). Moscú: Progreso.

Brougerè, G. (1998). Jogo e educação. Porto Alegre, RS: Artes Médicas.

Carleto, E. A. (2000). Porque brincar é coisa séria: o lugar do lúdico nas práticas escolares e na formação do educador. Dissertação de Mestrado, Programa de Pós-Graduação em Educação, Universidade Federal de Uberlândia, Minas Gerais.

Carvalho, L. M. M. (1999) Importância da brincadeira no desenvolvimento infantil segundo professores de pré-escolas (Terezina-PI). Dissertação de Mestrado, Programa de Pós-Graduação em Educação, Pontifícia Universidade Católica de São Paulo, São Paulo.

Elkonin, D. B. (2009). Psicologia do jogo. (2a ed., A. Cabral, trad.). São Paulo, SP: Martins Fontes.

Elkonin, D. B. (1987). Problemas psicológicos del juego em la edad escolar. In n V. Davidov, \& M. Suare (Orgs.), La psicología evolutiva y pedagógica en la URSS: Antología (pp. 83-102). Moscou: Progresso.

Ignatiev, E. I. (1960). La imaginación. In Smirnov, A. A., Leontiev, A. N., \& Rubstein, S.L. Psicologia (pp. 308-337). Cuba: Imprensa Nacional de Cuba.

Kratsova, E., \& Kratsov, G. (2010). Play in L. S. Vygotsky non-classical psychology. Journal of Russian and East European Psychology, 48(4), 25-41.

Marcolino, S. (2014). A mediação pedagógica na educação infantil para o desenvolvimento da brincadeira de papéis sociais. Tese de Doutorado, Programa de Pós-Graduação em Educação, Universidade do Estado de São Paulo, Marília.

Martins, C. A. (2009). A participação das crianças e da professora na constituição da brincadeira na educação infantil. Tese de doutorado, Programa de Pós-Graduação em Educação, Universidade Federal do Ceará, Fortaleza.
Martins, E. F. (2010). Formação de professores e violência nas escolas. Tese de Doutorado, Programa Pós-Graduação em Educação: Psicologia da Educação, Pontifícia Universidade Católica de São Paulo, São Paulo.

Martins, L. M.; \& Eidt, N. M. (2010). Trabalho e atividade: categorias de análise na psicologia histórico-cultural do desenvolvimento. Psicologia em Estudo, 15(4), 675-683.

Mello, S. A.(2007). Infância e humanização. Perspectiva, 25(1), 83-104.

Mukhina, V. (1986). Psicologia da idade pré-escolar. São Paulo, SP: Martins Fontes.

Navarro, M. S., \& Prodócimo, E. (2012). Brincar e mediação na escola. Revista Brasileira de Ciências do Esporte, 34(3), 633-648.

Petroviski, A. (1980). Psicologia general. Moscou: Editorial Progresso.

Rocha, M. S. M. L. (1994). A constituição social do brincar: Modos de abordagem do real e do imaginário no trabalho pedagógico. Dissertação de Mestrado, Programa de Pós-Graduação em Educação, Universidade Estadual de Campinas, Campinas.

Santos, A. K. (2005). Um estudo sobre brincadeira e contexto no agreste sergipano. Dissertação de Mestrado, Programa de Pós-Graduação em Psicologia, Universidade Federal da Bahia, Salvador.

Seixas, A. A. C. (2007). Brincando na I/ha dos Frades. Dissertação de Mestrado, Programa de Pós-Graduação em Psicologia, Universidade Federal da Bahia, Salvador.

Silva, A. A. (2008). Significados e o lugar do brincar na escola: A perspectiva da criança. Tese de Doutorado, Programa de PósGraduação em Educação Universidade Metodista de Piracicaba, Piracicaba.

Teixeira, S. R. (2012). A mediação de uma professora de Educação Infantil nas brincadeiras de faz de conta de crianças ribeirinhas. In Anais da 35a Reunião Anual da Associação Nacional de Pesquisa em Educação, Porto de Galinhas, PE. 
Teixeira, S. R. S., \& Alves, J. M. (2008). O contexto das brincadeiras das crianças ribeirinhas da Ilha do Combu. Psicologia: Reflexão e Crítica, 21(3), 374-382.

Tonet, I. (2009). Ética e capitalismo. Recuperado em 19 de setembro de 2009, de http:// www.xpg.com.br/arquivos/ETICA_E_ CAPIATLISMO.pdf

Vygotski, L. S. (2008) A brincadeira e o seu papel no desenvolvimento psíquico da criança. Revista Virtual de Gestão de Iniciativas Sociais, 8, 23-36.

Vigotsky, L. S. (2012). Imaginación y el arte en la infancial. (11a ed.). Madrid: Akal.
Vigotsky, L. S. (1995). Obras escogidas. Madrid: Visor.

Wajskop, G. (1990). Tia me deixa brincar? O espaço do jogo na educação pré-escolar. Dissertação de Mestrado Programa PósGraduação em Educação: Psicologia da Educação, Pontifícia Universidade Católica de São Paulo, São Paulo.

Zaporózhets, A. V. (1987). El desarrollo de la personalidad en el niño pré-escolar. V. Davidov, \& M. Suare (Orgs.), La psicología evolutiva y pedagógica en la URSS: Antología (228-249). Moscou, Editorial Progresso. 